\title{
A educação de jovens e adultos na indústria: formando a mão-de-obra brasileira para o século XXI
}

\author{
Leonardo Spicacci Campos ${ }^{1}$, Marta Maria Assumpção Rodrigues ${ }^{2}$
}

\footnotetext{
${ }^{1}$ Gestão de Políticas Públicas. Escola de Artes, Ciências e Humanidades (EACH-USP).

${ }^{2}$ Escola de Artes, Ciências e Humanidades (EACH-USP). Guest Scholar, Kellogg Institute (outono de 2011).

Correspondência: $\quad$ E-mail: mmar@usp.br Escola de Artes, Ciências e Humanidades (EACH-USP)

Av.Arlindo Béttio, 1000 - CEP: 03828-000 - São Paulo - SP - Brasil
}

\begin{abstract}
Resumo O presente artigo procura caracterizar a educação de jovens e adultos (EJA) oferecida pelo Serviço Social da Indústria (SESI), analisando-a enquanto parte de uma estratégia da classe industrial brasileira para o país no âmbito do Programa Educação para a Nova Indústria, lançado em 2007. Objetiva-se compreender de que formas a Indústria pretende alcançar o duplo objetivo de suprir as deficiências educacionais da mão-de-obra brasileira e formar o trabalhador para lidar com as demandas do modelo de produção flexível. Conclui-se que a educação de jovens e adultos, modalidade educacional historicamente negligenciada pelo Estado, possui um papel central na estratégia de desenvolvimento da Indústria para o país, não apenas como meio de elevação da escolaridade da mão-de-obra nacional, como também por representar um meio de difusão de uma visão de mundo e do trabalho associada aos valores de um novo modelo produtivo.
\end{abstract}

Palavras-chave: educação de jovens e adultos, SESI, reestruturação produtiva.

Abstract

This article aims at analyzing the youth and adult education program (Educação de Jovens e Adultos) offered by the Industry Social Service (Serviço Social da Indústria - SESI) as part of a strategy conceived by the Brazilian industrialists under the Education for the New Industry Program (Programa Educação para a Nova Indústria), launched in 
2007. It attempts to improve our understanding about the ways the industrialists are addressing the problem of educational deficiencies of the Brazilian workers, in a context of a more flexible model of production. It concludes that, in a policy area traditionally neglected by the state, the SESI youth and adult education program plays a central role in the industry developmental strategy. It is an efficient way not only to raise the educational level of the Brazilian workforce, but also to disseminate values that are related to a new model of production.

Keywords: youth and adult education, SESI, productive restructuring.

Resumen En este artículo se pretende caracterizar la educación de adultos (Educação de Jovens e Adultos) que ofrece el Servicio Social de la Industria (Serviço Social da Indústria - SESI), analizando como parte de una estrategia de la clase industrial brasileña en el ámbito del Programa Educación para la nueva industria (Educação para a Nova Indústria), puso en marcha en 2007. El objetivo es entender cómo la industria tiene la intención de lograr el doble objetivo de abordar las carencias educativas de la mano de obra y la forma de un trabajador brasileño listo para manejar las demandas de modelo de producción flexible. Se concluye que la educación de jóvenes y adultos, modalidad educativa históricamente postergada por el Estado, tiene un papel central en la estrategia de desarrollo para la industria del país, no sólo como un medio para elevar el nivel educativo de la mano de obra nacional, sino también para representar un medio de difusión de una visión del mundo y los valores relacionados con un nuevo modelo productivo.

Palabras-clave: educación de adultos, SESI, restructuración productiva. 


\section{Introdução}

Este artigo busca analisar a Educação de Jovens e Adultos (EJA) promovida pelo Serviço Social da Indústria (SESI) no estado de São Paulo, a partir do Programa para a Nova Indústria, lançado em 2007 com o objetivo de ampliar a escolaridade do trabalhador brasileiro em um ambiente de intensa globalização econômica. Pretende-se identificar também o papel da educação de jovens e adultos, segundo o projeto da Indústria para o Brasil, na formação do "novo trabalhador" no contexto do modelo produtivo da "Nova Indústria" e da chamada "sociedade do conhecimento".

Para traçar um amplo perfil sobre a educação de jovens e adultos do SESI e sua inserção dentro de um plano maior da Indústria para o Brasil, lançou-se mão de uma variedade de técnicas de pesquisa que incluíram a análise de publicações da Confederação Nacional da Indústria (CNI) e da Federação das Indústrias do Estado de São Paulo (FIESP), a realização de pesquisa de campo, com o acompanhamento de 12 aulas em diversos níveis em um centro educacional do SESI-SP na zona leste da cidade de São Paulo, entrevistas com atores envolvidos (gerente de EJA do SESI-SP, diretora, coordenadora pedagógica, professores e alunos) e análise do material didático utilizado pelo SESI: teleaulas e apostilas do Telecurso e do Programa de Alfabetização Intensiva (PAl).

O presente estudo divide-se em três partes. A primeira apresenta um panorama da Indústria no Brasil frente à "pobreza" do capital humano e um breve histórico da relação entre o SESI e a educação de jovens e adultos. A segunda parte trabalha o funcionamento e a estrutura da educação de jovens e adultos ofertada pela entidade em nível nacional e, mais especificamente, no estado de São Paulo.

Na última parte discute-se a construção do "novo trabalhador", segundo a concepção do Programa Educação para a Nova Indústria. Nas considerações finais tecemos um balanço crítico dos resultados relativos à atuação do SESI na educação de jovens e adultos, com foco em São Paulo, local de realização da pesquisa que representa o maior e mais poderoso departamento regional da instituição.

\section{A indústria e a "pobreza" do capital humano no Brasil}

O destaque dado à educação - e, em especial, à educação de adultos - no discurso da classe industrial brasileira remonta às primeiras décadas do século $X X$, sendo anterior, inclusive, ao surgimento das organizações patronais do setor no país. Roberto Simonsen, considerado o patrono dos industriais brasileiros, já lamentava, em discurso na Assembleia Nacional Constituinte de 1934, a pobreza da mão-de-obra brasileira em termos de qualificação, apontando a educação deficiente e a falta de higiene como causas da pobreza e propondo a criação de 
escolas para adultos com o objetivo de aumentar a produtividade do trabalhador nacional (Weinstein 2000:100).

Essa preocupação com a preparação da força de trabalho brasileira motivou a criação do Serviço Nacional de Aprendizagem Industrial (SENAI) em 1942, atuando no ramo da educação profissional. No entanto, logo ficou evidente que não seria o bastante oferecer formação profissional a uma classe trabalhadora que carecia das noções mais elementares que uma escolarização básica poderia garantir.

Assim, em 1947, o Serviço Social da Indústria (SESI), em seu segundo ano de existência, iniciou sua atividade educacional com os chamados Cursos Populares, que englobavam "alfabetização de adultos, educação moral e cívica e instrução complementar" (SESI 2011). Os cursos logo se tornaram um sucesso, estendendo-se para o interior do estado de São Paulo. Segundo Weinstein (2000:257), em 1955, havia 431 Cursos Populares em funcionamento no estado, com mais de 20 mil alunos matriculados.

A atuação da Indústria na educação de jovens e adultos foi progressivamente expandida ao longo das décadas seguintes. Um marco importante é o ano de 1994, quando o SESI passou a utilizar o Telecurso, metodologia de ensino a distância produzida por uma parceria entre a FIESP e a Fundação Roberto Marinho (ligada às Organizações Globo) para os níveis fundamental e médio.

O Telecurso consiste em um sistema de ensino a distância baseado no uso da mídia televisiva e voltado para pessoas que não concluíram o ensino fundamental ou o ensino médio na idade considerada adequada. Composto por teleaulas de 15 minutos, lança mão de recursos consagrados na teledramaturgia brasileira, bem como de atores famosos da televisão, para transmitir de forma objetiva e condensada os conteúdos desses níveis de ensino. Em seus quase 20 anos de existência, o Telecurso firmou-se como um dos maiores sistemas de educação de massa do mundo, atingindo 5,5 milhões de pessoas em quase 28 mil telessalas no Brasil (Telecurso 2011), tendo sido adotado, inclusive, na rede pública em vários estados e municípios do país.

No entanto, apesar do alcance das ações da Indústria e dos avanços significativos verificados sobretudo a partir da década de 1990 graças a políticas governamentais, o problema educacional brasileiro está longe de ser resolvido, ainda mais quando se trata da população adulta. Se atualmente é possível dizer que o país se encontra perto de universalizar o acesso das crianças à educação fundamental, foi feito relativamente pouco esforço no oferecimento da educação formal à população adulta.

Em 2009, segundo dados da Pesquisa Nacional por Amostra de Domicílios (PNAD), a população brasileira com 15 anos ou mais de idade tinha em média 7,6 anos de estudo (ou seja, ensino fundamental incompleto). Ainda segundo a PNAD, 14,7 milhões de brasileiros eram analfabetos, o que representava $8,9 \%$ da 
população com 10 anos ou mais. Entre os maiores de 25 anos, essa taxa era de 12\% (IBGE 2010).

Em termos qualitativos, a situação é igualmente ruim. Exames internacionais mostram que, apesar dos avanços consideráveis, os estudantes brasileiros se encontram em uma situação de grande desvantagem em termos de nível de conhecimento em relação a estudantes de países desenvolvidos. Entre esses exames, destaca-se o Programme for International Student Assessment (PISA), realizado pela Organização para a Cooperação e Desenvolvimento Econômico (OCDE), que comparou, em 2009, o desempenho de estudantes de 65 países em Leitura e Escrita, Matemática e Ciências Naturais (OECD 2010).

Em que pese a considerável expansão do sistema de ensino e a melhora nas estatísticas educacionais no Brasil, é inegável que esse progresso ainda é insuficiente para acompanhar e dar suporte ao crescimento econômico do país. Estudos indicam que a baixa escolaridade da mão-de-obra seria suficiente para explicar 35\% da diferença na renda per capita entre Brasil e Estados Unidos, 66\% da diferença entre Brasil e Japão e $89 \%$ da diferença entre Brasil e Chile (CanêdoPinheiro et al. 2007:14).

O atraso da educação brasileira tem se tornado ainda mais grave à medida que aumenta a participação de produtos de alta tecnologia no comércio mundial. Segundo relatório do Banco Mundial, de 1976 a 2003, a presença de produtos de média-alta e alta tecnologia no mercado internacional aumentou de $33 \%$ para $64 \%$ (Rodríguez et al. 2008:2). Nesse contexto, o conhecimento - não mais recursos naturais ou mão-de-obra barata - constitui, progressivamente, a essência da vantagem competitiva de um país, fazendo do déficit educacional cada vez mais um fator de atraso. Os impactos desse fenômeno já começaram a ser sentidos pelo empresariado brasileiro, que se vê na necessidade de compensar, através de seus próprios meios, a defasagem de conhecimentos de sua mão-de-obra, como mostra um relatório do Banco Mundial:

“... Brazilian firms do invest significant time and resources training their employees; however, in most cases this training focuses on basic skills deficits that should have been addressed by formal education system, not on the introduction of innovation to improve productivity on the shop floor" (Rodríguez et al. 2008:8).

Um fenômeno relacionado a essa realidade é o chamado "apagão de mão-deobra qualificada", que representa a combinação de uma taxa de desemprego relativamente alta com a existência de vagas ociosas para funções de média e alta qualificação. Essa realidade, além de funcionar como um obstáculo ao crescimento industrial, é prejudicial à lucratividade do empresário, que se vê na 
necessidade de, na sua visão, "sobrevalorizar" determinados profissionais para não perder sua participação no mercado.

Diante dessa situação, a Confederação Nacional da Indústria (CNI) lançou, no ano de 2007, o Programa Educação para a Nova Indústria, um plano ambicioso para superação (ou, ao menos, minimização) do atraso do capital humano nacional. Sua meta era atingir 16,2 milhões de matrículas no período 2007-2010, sendo 7,1 milhões na educação básica e continuada através do SESI e 9,1 milhões na educação profissional oferecida pelo SENAI (CNI 2007:7).

A educação de jovens e adultos tem um papel central no Programa. A meta para EJA era de nada menos que 2,3 milhões de conclusões até 2010, com 853 matrículas/conclusões (ou seja, conclusões de alunos que ingressaram no SESI nesse período). As vagas seriam preenchidas de modo a suprir $40 \%$ da demanda por ensino fundamental e $30 \%$ da demanda por ensino médio entre os trabalhadores da Indústria. Outras 600 mil vagas seriam destinadas a dependentes de trabalhadores e à comunidade em geral. O orçamento previsto era de mais de 3,5 bilhões de reais (CNI, 2007:24).

Mais do que fornecer os conhecimentos referentes à educação básica, a Indústria acredita que a educação deve se adaptar às necessidades do "mundo globalizado", que exige um novo perfil de trabalhador e cidadão. Segundo o Sumário Executivo do Programa Educação para a Nova Indústria,

"É imprescindível prover um ambiente de geração e disseminação de conhecimentos em grande escala, fundado no acesso amplo às tecnologias de informação e comunicação (TICS), no desenvolvimento de competências profissionais adequadas às necessidades do setor produtivo e no fomento ao empreendedorismo e à criatividade" (CNI 2007:8).

Para tal, a Indústria não hesita em utilizar em suas publicações, termos como "revolução" e "radicalização" para o sistema educacional. Segundo o Mapa Estratégico da Indústria (documento que serviu de base para o Programa Educação para a Nova Indústria), "o aumento da competitividade e da capacidade de inovação dependem do equivalente a uma revolução no sistema de educação" (CNI 2005:14). A Carta da Indústria, documento que reflete as visões predominantes no 4 을 Encontro Nacional da Indústria, realizado em 2009, propõe "Elevar a qualidade da educação" como a ação número um no longo prazo e "radicalizar na educação" como procedimento "fundamental para a cidadania e para a formação de uma indústria inovadora e competitiva" (CNI 2009:8). 


\section{A educação no SESI: funcionamento e estrutura}

No SESI, a educação de jovens e adultos é oferecida gratuitamente nos centros de atividades e centros educacionais do SESI e aberta a toda a comunidade nos níveis de alfabetização, do ensino fundamental e do ensino médio. A instituição oferece também, gratuitamente, a educação de jovens e adultos em empresas e espaços cedidos por organizações da sociedade civil, mediante demanda dos interessados.

A alfabetização de jovens e adultos pelo SESI-SP ocorre através de uma metodologia exclusiva, o Programa de Alfabetização Intensiva (PAl), que tem como foco o desenvolvimento das capacidades discursivas dos alfabetizandos, sendo composto por dois níveis de ensino. A Fase I corresponde aos alunos chamados não-alfabéticos, ou seja, aqueles que não foram alfabetizados completamente. A Fase II corresponde aos alunos já alfabetizados, mas sem o domínio completo da linguagem. O PAl focaliza também nas habilidades matemáticas dos alunos - um pré-requisito para que eles sejam aprovados e passem para a etapa seguinte na sua trajetória escolar.

Como exposto anteriormente, a educação de jovens e adultos para o ensino fundamental e o ensino médio é oferecida pelo Telecurso, metodologia que se tornou a marca do ensino da Indústria. Em 2006, o Telecurso 2000, criado em 1994, passou por uma reformulação, derivada da necessidade de ampliar e atualizar alguns conteúdos.

Em geral, o Novo Telecurso apresenta as mesmas teleaulas do Telecurso 2000, apenas atualizando certas informações. O projeto gráfico dos livros foi reformulado, tornando-os mais atraentes e todas as fitas de vídeo (VHS) foram transformadas em DVDs.

Uma das mudanças de maior impacto foi a inclusão de cinco novas disciplinas no ensino médio: Filosofia, Sociologia, Artes Plásticas, Teatro e Música. Embora deva-se ressaltar que, na prática, essas disciplinas sejam deixadas em segundo plano, pelo pouco tempo de aula e a prioridade dada pelos alunos em geral às disciplinas de exatas.

O ensino contextualizado pode ser considerado a ênfase não só do Telecurso, mas do ensino industrial de uma forma geral. Tanto as aulas do Telecurso quanto os conteúdos e o material didático do PAl são apresentados através de histórias em que trabalhadores, protagonistas, tentam resolver problemas do dia-a-dia. A análise do material didático do Telecurso, por exemplo, deixa bastante clara a preocupação da aplicação do conhecimento a situações práticas, sobretudo do mundo do trabalho e, mais particularmente, do mundo da fábrica.

Em 2010, o SESI-SP possuía quase 70 mil alunos matriculados na educação de jovens e adultos, distribuídos da seguinte maneira: $12 \%$ em salas de alfabetização, $44,5 \%$ no ensino fundamental e $43,5 \%$ no ensino médio, 
distribuídos em 834 turmas, conforme dados fornecidos pela gerente de educação de jovens e adultos do SESI-SP em julho.

Além das turmas citadas acima, no mesmo período havia aproximadamente cem turmas do Telecurso alocadas em empresas. Nesses lugares, normalmente são utilizados professores do próprio SESI e as aulas são realizadas em locais adaptados para se tornarem salas de aula.

Em geral, as telessalas do SESI são solicitadas pelas próprias empresas, através dos departamentos de recursos humanos. Para a gerente de EJA do SESI-SP, a busca pela qualificação dos funcionários seria justificada por uma preocupação em aumentar a qualidade de seus produtos fabricados.

Estudos sobre a educação do SESI apontam que, em empresas, o perfil dos alunos tende a ser mais homogêneo, as turmas menores, com maior taxa de conclusão e melhor desempenho (Florêncio 2003:35-36). Segundo Oliveira et al. (s/d), as taxas de conclusão no Telecurso 2000 em firmas de São Paulo chegaram de $84,1 \%$ e $93,8 \%$ para os níveis fundamental e médio, respectivamente.

A ponte entre o nível estratégico e tático-operacional na Divisão de Educação do SESI-SP é feita através dos chamados supervisores, responsáveis pelos aspectos administrativos e legais das escolas do SESI. Também subordinados à gerência estão os analistas, responsáveis pelo acompanhamento pedagógico junto a coordenadores e professores nas unidades escolares.

A existência desse tipo de profissional acaba sendo, justamente, um dos maiores diferenciais da educação do SESI frente ao ensino público. Nas visitas periódicas que faz às escolas, o analista conversa com os professores para identificar eventuais dificuldades ocorridas na sala de aula e verificar se a metodologia está sendo seguida adequadamente.

Esse "controle" por parte do analista parece ser bem visto pelos professores, na medida em que eles sentem-se mais seguros para o exercício do seu ofício. Uma professora do PAl, que também trabalha na rede estadual de ensino, compara a forma de organização de ambos:

"Eu gosto de trabalhar no SESI. Acho um trabalho sério, bem elaborado. Você sabe o que você tem que dar, e como se dar. Além disso, você tem todo o suporte que você precisa, não é uma professora que dá aula aleatoriamente. Você tem um parâmetro a seguir, um objetivo a atingir, uma linha de trabalho, bem diferente do Estado. No Estado não tem a cobrança e a orientação de como você tem que trabalhar. Você trabalhava do jeito que quiser. Não é como aqui, que tem orientação e acompanhamento. Nós sabemos que nós temos que cumprir as determinações". 
Nas escolas, a maior autoridade é o administrador escolar, auxiliado pelo coordenador pedagógico (as funções de um e de outro são semelhantes às de supervisores e analistas, respectivamente, mas circunscritas ao espaço da escola). A gestão financeira e de recursos humanos é centralizada.

A contratação de professores ocorre por meio de concursos já voltados para a modalidade de ensino correspondente. Isso significa que um professor da educação de jovens e adultos já é inscrito especialmente para essa modalidade de ensino. Os selecionados nesse concurso passam, primeiramente, por uma formação inicial, com carga-horária de 9 horas, em que são apresentados à metodologia e às formas de trabalho do SESI.

Há uma preocupação com a formação continuada dos professores através de cursos presenciais ou por meio da internet sobre diversos temas, oferecidos várias vezes ao ano. O SESI-SP também oferece a todos seus professores um notebook.

No SESI-SP, O Telecurso é oferecido na modalidade semipresencial, de modo que a presença às aulas não é obrigatória. Isso é apontado pelos seus gestores como uma dificuldade para o fornecimento de dados mais precisos sobre taxa de evasão e aprovação dos alunos do SESI nas provas de conclusão, uma vez que não é possível separar os alunos que realmente frequentam as aulas daqueles que estão apenas matriculados. No caso da evasão, o problema está no fato de que não há um critério definido para se considerar um aluno desistente.

As aulas do Telecurso ocorrem de segunda a sexta e duram duas horas por dia, normalmente das $19 \mathrm{~h} 30$ às $21 \mathrm{~h} 30$. No PAl, a aula tem uma duração de duas horas e meia, tendo início às $19 \mathrm{~h}$. Além da carga em sala de aula, os professores do Telecurso (cujo denominação mais correta é "orientadores de aprendizagem") cumprem uma hora diária de trabalho antes da aula no chamado horário pedagógico, que deve ser dedicado ao planejamento das aulas. No PAl, o horário pedagógico é de apenas meia-hora. Há bastante liberdade para o planejamento dos conteúdos pelo professor, desde que seja seguida a dinâmica definida pelo SESI.

Não há nenhuma forma de avaliação dos alunos na escola. A obtenção do certificado depende da aprovação nos exames, oferecidos pelo próprio SESI (que possui autorização do Conselho Estadual de Educação para tal) ou pelo Estado.

Como forma de apoio pedagógico, o SESI-SP oferece um serviço de 0800 (TiraDúvidas), que, segundo a gerente de EJA, é bastante utilizado. Em 2010, começou a funcionar também o Portal Educacional do SESI-SP, voltado para a comunicação e complementação da formação de alunos e funcionários. Através dele, o SESI-SP ampliou o alcance de suas estratégias educacionais a todos os principais meios de comunicação: televisão, internet, correspondência, telefone e fax. 
Para a gerente de EJA do SESI-SP, segundo entrevista feita em meados de 2010, o principal objetivo para a EJA dentro da instituição é a ampliação da demanda, buscando intensificar a divulgação e definir novas formas de "captar" potenciais alunos. De fato, o SESI realizou, durante a segunda metade de 2009, uma forte campanha publicitária para atrair alunos para a EJA, através de anúncios em lugares de grande circulação, como trens e metrôs na cidade de São Paulo.

Uma estratégia mais tradicional de divulgação da EJA no SESI é a montagem de estandes nas escolas durante o período em que são abertas as inscrições para que crianças da comunidade concorram a uma vaga na escola. Por meio deles, procura-se atingir os pais dessas crianças, entre os quais é bastante comum haver pessoas sem a educação básica completa.

Seja como for, os resultados mostram que o SESI vêm alcançando êxito razoável em atrair novos alunos. Segundo a gerente de EIA do SESI-SP, a meta do SESI-SP para EJA em 2010 era de 65 mil matrículas. Só até julho, já haviam conseguido 61 mil. Em termos nacionais, o SESI também tem sido bem-sucedido no cumprimento das metas do Programa Educação para a Nova Indústria. Em termos percentuais, a aplicação dos recursos do SESI em educação atingiu a meta prevista para 2014, que já foi ultrapassada na maior parte dos departamentos regionais (SESI 2011:16-17).

\section{Construindo o "novo trabalhador"}

Compreender o papel da educação de jovens e adultos na estratégia da Indústria brasileira para o país implica também entender qual é o perfil de trabalhador desejado pelos industriais, não apenas com relação ao exercício de suas funções na fábrica, como também na sua visão política e no seu cotidiano, como explicita o documento de lançamento do Programa Educação para a Nova Indústria:

"Formar capital humano significa não apenas preparar as pessoas nas respectivas profissões, mas também investir na formação de hábitos e atitudes positivas em relação ao trabalho, à vida comunitária e ao regime democrático" (CNI 2007:37).

Desse modo, é importante localizar essa nova ênfase dada pela Indústria brasileira à educação de adultos no contexto do processo de reestruturação produtiva, com a substituição do paradigma taylorista-fordista pelo modelo toyotista, possibilitada pelo desenvolvimento tecnológico, o qual demanda um perfil de operário bastante diverso do anterior. 
O toyotismo ou, de modo mais geral, o modelo de produção flexível, consiste no modo de organização da produção industrial surgido no Japão após a II Guerra Mundial e difundido pelos países ocidentais a partir da década de 1970. Em contraste com o que acontece no modelo taylorista-fordista, até então predominante nas indústrias europeias e norte-americanas, a produção industrial no modelo flexível é definida a partir da demanda de mercado, não da produtividade da fábrica. É a chamada produção just-in-time, visando ao estoque-zero, que exige a constante realocação de funcionários em diversas funções na fábrica.

Dessa necessidade, surge a figura do trabalhador flexível, polivalente, capaz de intercambiar entre diversas funções, sendo responsável pelo funcionamento de várias máquinas, pelo controle de qualidade, pela manutenção dos equipamentos e até mesmo pela limpeza do local de trabalho (Oliveira 2006:26).

Além disso, ao contrário do trabalhador taylorista, limitado ao exercício de uma única função repetitiva, o trabalhador do modelo toyotista trabalha em equipe e é chamado a contribuir para o aprimoramento do processo produtivo por meio dos círculos de Controle de Qualidade (CCQs), reuniões realizadas periodicamente entre o nível gerencial e o nível operacional da fábrica. 0 objetivo é a chamada qualidade total, redução máxima do nível de erros de fabricação.

Esse processo de transição do modelo taylorista-fordista para o modelo flexível, chamado de reestruturação produtiva, significou, no campo da sociologia do trabalho, uma progressiva substituição da noção de "qualificação" pela de "competências". Enquanto a primeira concepção, mais estanque, relaciona-se aos conhecimentos necessários para o exercício de uma determinada função, a segunda pode ser definida sinteticamente como o "conjunto de conhecimentos, habilidades e atitudes a serem mobilizados para determinada atividade humana" (SESI 2007:25).

A ideia de competências permite "flexibilizar" a noção de qualificação, tornandoa menos rígida e mais individualizada, abarcando não apenas conhecimentos formais, mas habilidades e características individuais. Assim, a escolaridade passa a significar mais um indicativo da "capacidade de aprendizado" que uma credencial para o exercício de determinadas tarefas. Consequentemente, a ênfase é deslocada da educação técnica para a educação básica, que permite o desenvolvimento de uma mentalidade com maior receptividade ao novo; ressalta-se também a importância da educação continuada, fundamental em um cenário de constantes mudanças (Shiroma e Campos 1997:28).

Essa ênfase no "aprender a aprender" recebe bastante destaque no material didático do SESI, discurso que é reforçado pelos professores. ISso, porém, não ocorre apenas de modo explícito. As teleaulas do Telecurso se desenvolvem a partir da identificação de um problema pelo trabalhador (representado em seu ambiente de trabalho) e da tentativa de resolvê-lo. 
Sobre esse ponto, Wendorff (2004:84) destaca uma característica importante: "Em todas as aulas, os trabalhadores aparecem tentando resolver algum problema. Nunca há chefes ou gerentes para ajudar". O trabalhador representado nas aulas do Telecurso tem iniciativa e é capaz de encontrar soluções para problemas sozinho - ou, o que é mais comum, com a ajuda de outros trabalhadores, mas sem recorrer a um superior hierárquico. É o trabalhador capaz de dar sua colaboração em um CCQ ou através de canais permanentes de sugestões, filosofia tipicamente toyotista conhecida como kaizen.

Não é necessária, portanto, uma análise muito longa ou complexa para identificar de que modo as características do trabalhador toyotista são representadas no material didático do Telecurso: elas aparecem o tempo todo, de formas mais ou menos explícitas, nas dramatizações das teleaulas, nos conteúdos das mais diversas disciplinas e até mesmo nos exercícios.

Especialmente ilustrativo é o chamado Projeto TEC (nome fictício), projeto-piloto do SESI-SP elaborado em parceria com uma indústria dinamarquesa de brinquedos para os alunos de alfabetização. Nos dias em que o projeto era realizado (de duas em duas semanas, por dois dias consecutivos), os alunos eram divididos em três grupos. Em cada um deles, os alunos, além de trabalharem de forma cooperativa na montagem de máquinas utilizando blocos e peças de plástico, eram levados a procurar resolver por si mesmos os problemas que surgiam na montagem. Uma simulação, portanto, de uma célula de produção toyotista.

A apostila utilizada pelo projeto também fornece outros exemplos interessantes. Na primeira das cinco histórias em quadrinhos que a compõem, a personagem principal, Palmira, uma mulher negra moradora da periferia, após ser demitida do banco onde trabalhava, resolve fundar uma fábrica para reaproveitamento de materiais recicláveis com o dinheiro do seu Fundo de Garantia. Seu primeiro passo é ir a um curso do SEBRAE, no qual aprende as características de um bom empreendedor, entre as quais "Ser um profundo conhecedor do todo e não só de algumas partes" e "Ser ousado e fazer uso da criatividade". Além destas, a apostila destaca como qualidades do empreendedor, entre outras:

- Buscar oportunidades a demonstrar iniciativa, realizando atividades antes de ser solicitado ou forçado pelas circunstâncias.

- Comprometer-se com a realização das tarefas assumidas.

- Colocar, para si e para sua equipe, elevados padrões de qualidade a serem atingidos.

- Planejar e acompanhar rigorosamente tudo que está sendo executado.

Iniciativa, responsabilidade, polivalência, criatividade, observação de altos padrões de qualidade são algumas das características do empreendedor apresentadas na apostila e - não por acaso - são também aquelas esperadas do "novo trabalhador". 
A habilidade de resolução de problemas é o foco da seção "Situação-problema", na qual era proposto que os alunos aperfeiçoassem as máquinas construídas para aumentar sua produtividade ou sua eficiência, constituindo uma espécie de pequeno CCQ. Para que tivessem sucesso nessa tentativa, a apostila exigia conhecimento ou pelo menos algumas noções de mecânica, o que era ainda mais forte na seção "Conceitos Tecnológicos", na qual eram dadas algumas explicações sobre o funcionamento de máquinas, muitas vezes utilizando conceitos de física e termos de mecânica bastante complexos.

Esse tratamento relativamente aprofundado de conceitos tecnológicos evidencia a ênfase na "educação tecnológica" e a formação para o trabalho na indústria, desde o nível mais básico de educação. Observa-se que o conteúdo da educação de jovens e adultos oferecida pela Indústria e até mesmo a metodologia utilizada estão intimamente ligadas às demandas do setor produtivo por um novo perfil profissional.

Para além do mundo de trabalho, a análise do material didático utilizado pelo SESI também diz muito sobre a visão de mundo da classe industrial. As representações e assuntos tratados em apostilas e teleaulas frequentemente carregam um diagnóstico e uma prescrição para o país, tomando o capitalismo como pressuposto e a educação como panaceia para os problemas socioeconômicos nacionais e mundiais, além de, é claro, a chave para o sucesso do trabalhador. É o que mostra o seguinte trecho da apostila do Projeto TEC:

"Com um mercado cada vez mais especializado, a mão-de-obra exigida também é cada vez mais qualificada, isto é, o trabalhador cada vez mais precisa estar preparado pra exercer uma determinada tarefa. Sabendo disso tudo, dá pra gente entender por que é tão importante investir em educação. Assim, o trabalhador, além de conseguir emprego, pode melhorar de função e de salário".

Da mesma forma, o trabalhador que não se atualiza é, inevitavelmente, deixado para trás, perdendo em empregabilidade, outro conceito (essencialmente individualizante) relacionado à noção de competências. Nas apostilas do SESI, o desemprego não aparece como sendo relacionado a fatores estruturais, mas à falta de atualização da mão-de-obra, como mostra o seguinte trecho da apostila do Projeto TEC, que fala sobre o êxodo rural:

"Com o tempo, a mecanização das lavouras passou a exigir mãode-obra especializada, e os trabalhadores rurais, que não acompanharam essas evoluções, foram perdendo espaço e, por fim, o emprego"[ grifo nosso]. 
Após apresentar o significado do termo "êxodo rural" e falar dos problemas encontrados pelos migrantes nas cidades (onde acabariam "com frequência tornando-se moradores de rua"), a apostila ressalta:

\begin{abstract}
"Essa realidade é contrastante com a evolução tecnológica, que acontece a todo instante; por isso, é fundamental que as pessoas criem consciência de que elas precisam especializar-se e, cada vez mais, tornar-se qualificadas para atender às necessidades dos novos tempos. Afinal, a modernização acontece em todos os cantos!".
\end{abstract}

Nas apostilas e teleaulas do Telecurso, ser patrão ou empregado é implicitamente representado como uma questão de escolha, algo que a apostila do Projeto TEC diz explicitamente: “Algumas pessoas preferem o emprego, que aparentemente é mais estável. Por isso, submetem-se a realizar tarefas sob o controle de seus superiores, enquanto outras optam pela autonomia".

As questões sociais e políticas também são tratadas tanto no Telecurso quanto na apostila do Projeto TEC, na qual o debate sobre a desigualdade social e racial se dá nos seguintes termos:

"Ainda hoje os reflexos da escravidão estão evidentes: os negros foram jogados das senzalas para as favelas e as suas famílias, em sua maioria, ainda mantêm-se lá. Os índios perderam seu espaço e estão cada vez mais reclusos em suas reservas. E muitos ricos estão cada vez mais ricos às custas dos pobres".

A solução proposta pela apostila é a "conscientização" do eleitor na hora de votar, como mostra o trecho a seguir:

\footnotetext{
"Para tentar reparar essas falhas históricas são eleitos os vereadores, deputados e senadores. São eles que fazem as leis e lutam pelos interesses da população. Assim, a justiça social fica nas mãos dos políticos, e cada vez mais temos de ser críticos e estar atentos às nossas escolhas (...) Só assim conseguiremos buscar uma verdadeira justiça social!".
} 
Observa-se, de forma clara, a restrição da democracia e da participação popular ao exercício do voto. Além disso, quando se trata da relação entre patrões e empregados, a apostila defende o que chama de "pacto social", que permitiria "buscar um maior equilíbrio entre os interesses dos diversos grupos sociais", através da estruturação de políticas de aumento salarial "compatíveis com o crescimento econômico".

Seja qual for o assunto, se não estiver diretamente relacionado com a atividade da Indústria, tende a ser pautado pelo senso-comum. Não se nega a existência do racismo ou da desigualdade social, por exemplo. Mas também não se toma o cuidado de se analisar esses problemas com mais profundidade.

Um exemplo ilustrativo é de uma teleaula de geografia do ensino médio, na qual condenam-se as "elites políticas" do país, que gastariam excessivamente em obras e compras de material bélico em detrimento da educação e da saúde.

Assim, o discurso da Indústria no seu material educativo só vai até o ponto em que há consenso social ("Devemos reduzir a desigualdade", "A pobreza deve ser combatida", etc.). A própria ênfase dada à educação é um exemplo disso. Como mostrado por Rodrigues (1998:130), essa passou a ser o novo télos da classe industrial, no sentido de uma "imagem construída pelo discurso hegemônico com o fito de se tornar uma meta a ser perseguida incansavelmente pelo conjunto da sociedade, conduzida pela classe que o elaborou".

Segundo Rodrigues (1998), a indústria teria realizado, nas últimas décadas, uma metamorfose teleológica para se colocar acima dos discursos antagônicos de classe, tratada como principal medida para solucionar os problemas sociais do Brasil, sem que seja feito um questionamento mais aprofundado sobre as raízes da desigualdade social no país. Cria-se, assim, uma cidadania do consenso, como destaca Carvalho (1999:88):

"A contextualização do ensino informada pelo mundo do trabalho acaba por delimitar o conceito de cidadania ao mundo da fábrica, com suas contradições e conflitos que caracterizam as relações sociais capitalistas (...). Dessa forma, desenvolve uma cidadania que reforça as relações sociais que esse mundo projeta".

\section{Considerações finais}

Embora tenha obtido avanços quantitativos desde o início do século $X X$, tendo praticamente alcançado a universalização do acesso ao ensino fundamental, a educação brasileira ainda apresenta sérios problemas para se tornar efetivamente uma ferramenta para a preparação para o trabalho e a promoção da cidadania e da equidade social. 
A lentidão para se universalizar o ensino médio, a ainda forte elitização do ensino superior, as altas taxas de repetência e evasão e, principalmente, a péssima qualidade da educação básica no Brasil compõem um quadro preocupante, tanto da perspectiva econômica quanto sócio-política.

Sabemos que em um mundo marcado pela adoção de novas formas de produção e tecnologias, a educação básica de boa qualidade constitui uma ferramenta importante à disposição do Estado para intervir no processo de reprodução das desigualdades sociais, ampliar o escopo da igualdade de oportunidades e preparar o trabalhador brasileiro para o contexto de constantes mudanças e desafios impostos pela globalização.

No entanto, o cenário educacional do Brasil no início do século XXI tem como característica fundamental a baixa escolaridade da população, que vem se tornando cada vez mais um fator de perpetuação do atraso e desaceleração do crescimento econômico.

Nesse contexto, a classe industrial entra em ação, mais uma vez, como produtora de políticas públicas. Na verdade, públicas apenas em parte, já que atendem a interesses bastante particulares, embora possam, certamente, gerar externalidades positivas para o país. Dada a baixa eficácia das políticas públicas governamentais, a Indústria vê que, sob o custo de perda de sua competitividade, deve investir, ela mesma, na formação da mão-de-obra nacional.

Apesar das críticas que se deve fazer ao modo como a Indústria enxerga e realiza a educação de jovens e adultos, é impossível negar os consideráveis impactos da sua ação na erradicação do analfabetismo e na ampliação da escolaridade do trabalhador brasileiro.

Parte desse mérito pode ser explicado pelo fato de que, por natureza, sua ação na área educacional tem a vantagem de focar o aprendizado e não o certificado. Para a indústria, pouco interessa o número de trabalhadores com a educação básica completa se essa educação não fornecer as habilidades e competências básicas para o exercício do trabalho.

Há, portanto, na educação industrial uma preocupação com a qualidade do ensino oferecido, o que nem sempre acontece com o ensino público, ainda mais na educação de jovens e adultos, na qual pode ser bastante sedutor a alguns governantes ampliar o número de concluintes sem uma preocupação com a qualidade do ensino oferecido.

De fato, as avaliações feitas do SESI tanto por parte dos alunos quanto de seus funcionários é muito positiva. Nas entrevistas realizadas durante a pesquisa de campo, "seriedade" foi a palavra mais associada à instituição pelos entrevistados. 
Diferenciais como o material didático (com uso de recursos multimídia), a existência do horário pedagógico, os programas de formação continuada e, principalmente, e o apoio pedagógico ao planejamento e ao trabalho na sala de aula (tanto pela coordenadora quanto pelos analistas) são indicados como pontos mais positivos do ensino do SESI.

A instituição também foi bem avaliada pelos alunos, que fizeram elogios a seus professores e às diversas oportunidades dadas pela escola, como uma ida ao teatro e ao cinema (pela primeira vez para boa parte deles), sempre em comparação com o que viam nas escolas públicas nas quais estudavam anteriormente, em detrimento destas.

Assim, independentemente de nossa concordância (ou não) com a visão de mundo industrial sobre o mundo do trabalho ensinada através da EJA oferecida pelo SESI-SP, é inegável o fato de que a indústria foi, em um contexto de mau uso de recursos públicos e desinteresse governamental, uma das instituições brasileiras que mais a sério levou a educação de jovens e adultos nas últimas décadas.

Claro que, se o fez, não foi por sentimento de justiça ou dever moral, mas por seguir uma racionalidade estritamente econômica. Nesse sentido, o discurso da classe industrial, exposto em diversas publicações, é bastante franco: a educação deve ser garantida porque é necessária, antes de tudo, ao desenvolvimento econômico.

É justamente nesse ponto que está o perigo de deixar ao setor privado a responsabilidade por uma função essencialmente pública: o foco de um direito de cidadania acaba se perdendo ao ser substituído pela conveniência econômica. $O$ problema que esse critério acarreta é que, da perspectiva da cidadania, não é socialmente nem moralmente desejável uma educação just-in-time, ou seja, que apenas se efetive quando necessária ao crescimento econômico.

Nesse aspecto, pode-se identificar a maior falha do ensino industrial. Através da análise do material didático utilizado pelo SESI para a educação de jovens e adultos, foi possível notar um forte contraste entre a profundidade com que são tratados temas e conteúdos ligados ao mundo do trabalho e a superficialidade do tratamento dado a temas como cidadania, que é comumente restrita apenas à dimensão da participação política através do voto.

A história é ensinada de forma pouco crítica, o tratamento dos problemas socioeconômicos do país não foge do senso comum e a dinâmica de uma telessala abre pouco espaço para o diálogo e o debate, o que é reforçado pela deliberação explícita do Telecurso em evitar temas "para os quais não haja consenso social".

A discussão de direitos civis, políticos e sociais não se realiza entre os conteúdos da educação de jovens e adultos da Indústria, e isso não é, de forma alguma, um detalhe, na medida em essa modalidade educacional é voltada essencialmente 
para aqueles a quem tais direitos foram e permanecem sendo recorrentemente negados.

\section{Referências}

Canêdo-Pinheiro $\mathrm{M}$ et al. Por que o Brasil não precisa de política industrial. Ensaios Econômicos 644. Fundação Getúlio Vargas, 2007. Disponível na internet em: http://is.gd/9qOyNw [ Acesso em: 10 fev. 2011].

Carvalho CPF. A educação cidadã na visão empresarial: o Telecurso 2000. Campinas: Autores Associados, 1999.

Confederação Nacional da Indústria (CNI). Carta da Indústria. Documento apresentado no 4 을 Encontro Nacional da Indústria (ENAl). Brasília: CNI, 2009.

Confederação Nacional da Indústria (CNI). Educação para a Nova Indústria: proposta de ação do Sistema Indústria, em consonância com as diretrizes do Mapa Estratégico da Indústria. Brasília: CNI, 2007.

Confederação Nacional da Indústria (CNI). Mapa Estratégico da Indústria (20072015). Brasília: CNI, 2005.

Florêncio SRR. Projeto Telecurso 2000 e a qualificação do "novo" trabalhador. Dissertação (Mestrado). Faculdade de Educação (UNICAMP), 2003.

Freire P. Pedagogia do oprimido. São Paulo: Paz e Terra, 2005.

Instituto Brasileiro de Geografia e Estatística (IBGE). Pesquisa Nacional por Amostra de Domicílios 2009 - Síntese de Indicadores 2009. Rio de Janeiro: IBGE, 2010.

Machado LRS. Mudanças tecnológicas e a educação da classe trabalhadora. In: CBE. Trabalho e Educação. Campinas: Papirus, 1992.

Novo Telecurso, Website. 2011. Disponível na internet em: http://www.novotelecurso.org.br [ Acesso em: 30 nov. 2009].

Oliveira E. Toyotismo no Brasil. São Paulo: Expressão Popular, 2004.

Oliveira JBA, Castro CM, Verdisco A. Education by TV: Telecurso 2000. s/d.

Organization for Economic Co-operation and Development (OECD). P/SA 2009 at a glance. OECD Publishing, 2010. Disponível na internet em: http://www.oecd.org/dataoecd/31/28/46660259.pdf [ Acesso em: 10 jul. 2010].

Rodrigues J. O moderno príncipe industrial. Campinas: Autores Associados, 1998. 
Rodríguez A, Dahlman CJ, Salmi J. Knowledge and innovation for competitiveness in Brazil. Washington, DC: World Bank, 2008.

Serviço Social da Indústria - São Paulo (SESI-SP). Website. 2011. Disponível na internet em: http://www.sesisp.org.br [ Acesso em: 03 jan. 2010].

Serviço Social da Indústria (SESI). Apostila SESI - Programa de Educação Tecnológica. Zoom Editora Educacional, 2003.

Serviço Social da Indústria (SESI). O SESI, o trabalhador e a indústria: um resgate histórico. Estudos de Tendências Sociais - Observatório SESI. Brasília: CNI, 2008.

Serviço Social da Indústria (SESI). Políticas e diretrizes da rede SESI de educação. Brasília, 2007.

Serviço Social da Indústria (SESI). Relatório anual 2010. Brasília, 2011. Disponível na internet em: http://www.sesi.org.br/portal/main.jsp?lumChannelld=8A81818B146A9BCF01 146AC304262DE1 [Acesso em: 12 out. 2011].

Serviço Social da Indústria (SESI). Website. 2011. Disponível na internet em: http://www.sesi.org.br [ Acesso em: 04 jan. 2010].

Shiroma EO, Campos RF. Qualificação e reestruturação produtiva: um balanço das pesquisas em educação. Educação \& Sociedade 1997, 18(61):13-35.

Sofia J. Brasil enfrenta "apagão" de mão-de-obra qualificada. Folha de São Paulo, 14 fev. 2010. In: Buarque, Sen. Cristovam, Website. Disponível na internet em: http://www.cristovam.org.br/portal2 [ Acesso em: 12 jul. 2010].

Telecurso. Teleaula - TC Ensino Fundamental: Aula 21 (Geografia) - "Aquarela do Brasil".

Telecurso. Teleaula - TC Ensino Fundamental: Aula 24 (Geografia) - "A industrialização brasileira".

Telecurso. Teleaula - TC Ensino Fundamental: Aula 50 (Língua Portuguesa) "Assino ou não assino?".

Telecurso. Teleaula - TC Ensino Médio: Aula 18 (Geografia) - "Acompanhar as mudanças".

Telecurso. Teleaula - TC Ensino Médio: Aula 32 (Geografia) - "Robôs e engenheiros: para onde vão os operários?".

Telecurso. Teleaula - TC Ensino Médio: Aula 37 (Geografia) - "Os novos blocos políticos". 
Telecurso. Teleaula - TC Ensino Médio: Aula 38 (Geografia) - "A pobreza das nações".

Telecurso. Teleaula - TC Ensino Médio: Aula 40 (História) - "Estado e economia na İa República".

Telecurso. Teleaula - TC Ensino Médio: Aula 47 (História) - "A cultura do fim do século".

Telecurso. Teleaula - TC Ensino Médio: Aula 50 (História) - "A formação da sociedade industrial brasileira".

Weinstein B. (Re)formação da classe trabalhadora no Brasil. São Paulo: Cortez, 2000.

Wendorff TS. Ensinando a ser trabalhador: um estudo das representações no Telecurso 2000. Tese (Mestrado) - Universidade do Vale do Rio dos Sinos (UNISINOS), São Leopoldo, 2004. 